\title{
Podridão-vermelha-da-raiz da soja em cultivos com diferentes sistemas de manejo e coberturas do solo
}

\author{
Emerson Fábio dos Reis ${ }^{(1)}$, Adelino Pelissari(1), Anibal de Moraes ${ }^{(1)}$, \\ Edilson Batista de Oliveira ${ }^{(2)}$ e Lucimeris Ruaro(1)
}

\begin{abstract}
(1)Universidade Federal do Paraná, Rua dos Funcionários, no 1.540, Juvevê, CEP 80035-050 Curitiba, PR. E-mail: emerson.f.reis@monsanto.com, linopeli@hotmail.com, anibal.moraes@ufpr.br, lucimeris@ufpr.br (2)Embrapa Florestas, Estrada da Ribeira, Maracanã, CEP 83408-000 Colombo, PR. E-mail: edilson@cnpf.embrapa.br
\end{abstract}

\begin{abstract}
Resumo - O objetivo deste trabalho foi avaliar o efeito dos sistemas de manejo do solo e de coberturas de inverno sobre o número de propágulos de Fusarium spp. no solo, a incidência da podridão-vermelha-da-raiz (PVR) e a produtividade das cultivares de soja CD 206 e FT Fênix. Foram realizados dois experimentos nos anos agrícolas de 2006/2007 e 2007/2008. Utilizou-se o delineamento experimental de blocos ao acaso, em parcelas subsubdivididas, com três repetições. Foram avaliados dois sistemas de preparo do solo: plantio direto e revolvimento do solo na profundidade de $25 \mathrm{~cm}$. As coberturas de inverno utilizadas foram: aveia-preta, com duas densidades de plantio; aveia-preta + ervilhaca; azevém; e pousio. A incidência da doença, na safra de 2006/2007, na cultivar FT Fênix, foi menor que na CD 206. Na safra 2007/2008, não houve diferença significativa. Houve incremento na produtividade, de $125 \mathrm{~kg} \mathrm{ha}^{-1}$, com o solo revolvido, em comparação ao plantio direto. A cobertura com aveia-preta + ervilhaca apresentou maior número de propágulos de Fusarium spp. no solo, na safra de 2006/2007. No entanto, no segundo ano, essa diferença não foi observada. Os sistemas de preparo do solo e as coberturas de inverno utilizadas não influenciam a incidência da PVR em cultivares de soja ou o número de propágulos de Fusarium spp. no solo. O sistema com solo revolvido proporciona aumento de produtividade da soja, no segundo ano de manejo.
\end{abstract}

Termos para indexação: Fusarium, Glycine max, adubo verde, manejo do solo.

\section{Sudden death syndrome of soybean under different soil management systems and cover crops}

\begin{abstract}
The objective of this work was to assess the effect of soil management systems and winter cover crops on the number of propagules of Fusarium spp. in soil, the incidence of sudden death syndrome (SDS), and the productivity of the soybean cultivars CD 206 and FT Fênix. Two experiments were carried out in the 2006/2007 and 2007/2008 crop years. The experimental design was a randomized complete block in a split-split plot arrangement, with three replicates. Two soil tillage systems were evaluated: no-tillage and plowed soil at a depth of $25 \mathrm{~cm}$. The soil covers used were: black oat, with two planting densities; black oat + vetch; ryegrass; and fallow. The incidence of the disease in the 2006/2007 crop year in the cultivar FT Fênix was lower than in CD 206. In the 2007/2008 crop, there was no significant difference. There was an increase in productivity, of $125 \mathrm{~kg} \mathrm{ha}^{-1}$, in the plowed treatment, when compared to no-tillage. The cover with black oat + vetch showed a higher number of propagules of Fusarium spp. in soil in the 2006/2007 crop year. However, in the second year, this difference was not observed. The soil management systems and winter cover crops used do not influence the incidence of SDS in soybean cultivars or the number of Fusarium spp. propagules in soil. The plowed system provides an increase in soybean yield in the second year of management.
\end{abstract}

Index terms: Fusarium, Glycine max, green manure, soil management.

\section{Introdução}

A podridão-vermelha-da-raiz (PVR), também conhecida como síndrome da morte súbita, é causada pelo complexo de fungos que compreende quatro espécies de Fusarium: F. brasiliense sp. nov., $F$. cuneirostrum sp. nov. e $F$. tucumaniae sp. nov., encontradas em cultivos de soja (Glycine max L.) na América do Sul, e $F$. virguliforme sp. nov., na América do Norte (Aoki et al., 2005). Segundo Arruda et al. (2005), no Brasil, a espécie prevalente é a F. tucumaniae.

A PVR tem causado perdas significativas na produção de soja, no Brasil (Tecnologias de produção de soja, 2006). Para esse patógeno, não há opção de controle químico, e a rotação de culturas na área de cultivo não é eficaz (Silva et al., 2002). A resistência das cultivares à doença é parcial, uma vez que, sob alta pressão de inóculo, mesmo os genótipos com maior nível de resistência podem apresentar sintomas típicos

Pesq. agropec. bras., Brasília, v.47, n.4, p.528-533, abr. 2012 
da PVR (Mueller et al., 2002; Silva et al., 2002; Gásperi et al., 2003). No entanto, a rotação de culturas, com o uso de plantas de cobertura do solo, contribui para reduzir o ataque de pragas e doenças, que é mais intenso quando o cultivo de uma única espécie é realizado sucessivamente na mesma área (Gabriel Filho et al., 2003). A incorporação de matéria orgânica pode melhorar as características físicas e químicas do solo, aumentar a atividade e o tamanho da comunidade microbiana e ainda ter efeito no controle de fitopatógenos (Fenile \& Sousa, 1999; Baptista et al., 2007). Contudo, os fungos fitopatogênicos, como Fusarium spp., sobrevivem melhor em solo com restos de cultura enterrados (Almeida et al., 2001).

O objetivo deste trabalho foi avaliar o efeito dos sistemas de manejo do solo e de coberturas de inverno sobre o número de propágulos de Fusarium spp. no solo, a incidência da PVR e a produtividade das cultivares de soja CD 206 e FT Fênix.

\section{Material e Métodos}

Os experimentos foram conduzidos no campo, nos anos agrícolas de 2006/2007 e 2007/2008, da Fazenda Experimental da Fundação ABC, no Município de Ponta Grossa, PR $\left(25^{\circ} 00^{\prime} 48^{\prime \prime S ~ e ~}\right.$ $50^{\circ} 09^{\prime} 05^{\prime \prime} \mathrm{W}$, a $890 \mathrm{~m}$ de altitude), em Latossolo Vermelho distrófico (Santos et al., 2006a). O clima da região, conforme a classificação de Köppen, é do tipo $\mathrm{Cfb}$, ou seja, clima temperado propriamente dito, com temperatura média no mês mais frio de $18^{\circ} \mathrm{C}$, verões frescos e temperatura média no mês mais quente de $22^{\circ} \mathrm{C}$, sem estação seca definida (Caviglione et al., 2000).

Utilizou-se o delineamento experimental de blocos ao acaso, com parcelas subsubdivididas, com três repetições. Cada unidade experimental apresentava área total de 79,92 $\mathrm{m}^{2}(6,6 \times 12 \mathrm{~m})$. Nas parcelas, foram avaliados dois preparos de solo: plantio direto e revolvimento do solo na profundidade de $25 \mathrm{~cm}$, por meio de aerador tratorizado Aeromix, (Ikeda, Marília, SP), realizado no inverno antes da semeadura das plantas de cobertura de solo. Nas subparcelas, foram avaliadas quatro coberturas de solo e pousio. As coberturas do solo utilizadas foram: aveia-preta, com $40 \mathrm{~kg} \mathrm{ha}^{-1}$ de sementes; aveia-preta, com $80 \mathrm{~kg} \mathrm{ha}^{-1}$ de sementes e adição de $20 \mathrm{~kg} \mathrm{ha}^{-1}$ de $\mathrm{N}$, na forma de ureia; aveia-preta + ervilhaca, com $50 \mathrm{~kg} \mathrm{ha}^{-1}$ de sementes para cada espécie; e azevém, com $60 \mathrm{~kg} \mathrm{ha}^{-1}$ de sementes. Os tratamentos foram instalados no cultivo de inverno, em maio de 2006, referente à safra de $2006 / 2007$, e em maio de 2007, referente à safra $2007 / 2008$. As coberturas foram roladas com rolo-faca em setembro, antecedendo a semeadura da soja realizada em outubro de 2006 e 2007. No verão, cada subparcela da fase de inverno foi dividida em duas partes iguais, o que constituiu as subsubparcelas, onde foram plantadas as cultivares de soja CD 206 e FT Fênix.

A adubação do solo foi realizada com uso de $50 \mathrm{~kg} \mathrm{ha}^{-1}$ de $\mathrm{P}_{2} \mathrm{O}_{5}$ e $50 \mathrm{~kg} \mathrm{ha}^{-1}$ de $\mathrm{K}_{2} \mathrm{O}$. A densidade de plantio foi de 260 mil plantas por hectare (13 sementes por metro e espaçamento de $50 \mathrm{~cm}$ entre linhas). Todos os tratos culturais (aplicação de herbicidas, inseticidas e fungicidas) da soja foram realizados de acordo com Tecnologias de produção de soja (2006).

A avaliação do número de propágulos de Fusarium spp. no solo foi realizada antes da semeadura da soja, tendo-se utilizado o método do meio de Nash \& Snyder (1962), em amostras de solo coletadas na profundidade de 0 a $20 \mathrm{~cm}$, com uso de trado holandês, o que totalizou sete amostras por repetição. A incidência de Fusarium spp. foi determinada por meio da percentagem de plantas que apresentaram o sintoma no total de 20 plantas por parcela, no estádio fenológico R6 da soja, tendose observado o sintoma na área foliar, conhecido como folha carijó, que é caracterizado por manchas cloróticas e necróticas internervais, com coloração verde normal, na região das nervuras, e com coloração castanho-claro a castanho-avermelhado escuro, na raiz (Almeida et al., 2005). Após avaliadas, as plantas foram separadas de acordo com a presença ou a ausência de PVR. Realizouse a contagem do número de vagens e sementes por planta, tendo-se observado o número médio de vagens e grãos das plantas com e sem sintomas. Essa avaliação foi realizada na safra de 2007/2008, para a verificação da influência das variáveis em estudo, nos dois anos de cultivo.

Para a determinação da produtividade de soja, foram colhidas manualmente, trilhadas e pesadas 
duas linhas de $10 \mathrm{~m}$ de comprimento, com espaçamento de $0,45 \mathrm{~m}$, o que totalizou $9,0 \mathrm{~m}^{2}$ de área útil de cada parcela. Avaliou-se a massa de grãos por meio da pesagem de 100 sementes por parcela, tendo-se multiplicado o resultado por dez. Os dados foram corrigidos para $13 \%$ de umidade.

Os dados foram submetidos à análise de variância, e as médias foram comparadas pelo teste de Tukey, a $5 \%$ de probabilidade.

\section{Resultados e Discussão}

Não houve interação significativa entre os fatores avaliados. O plantio direto apresentou menor número de propágulos de Fusarium spp., em solo seco, na safra de 2006/2007, em comparação ao solo revolvido (Tabela 1). Esse resultado divergiu do de Toledo-Souza et al. (2008), que observou que o sistema plantio direto favorece o aumento da população de Fusarium spp. no solo. Entretanto, não houve diferença significativa entre os tratamentos na safra de 2007/2008. Na safra de 2006/2007, ao se considerar o período do segundo decêndio de fevereiro ao segundo decêndio de março, em que a cultura encontrava-se nos estádios mais suscetíveis à doença, isto é, do estádio R1 ao R6 (Farias Neto et al., 2006), verificou-se precipitação de $211 \mathrm{~mm}$ e temperatura média de $22,1^{\circ} \mathrm{C}$ (Figura 1 ). Já na safra de 2007/2008, no mesmo período, observou-se precipitação de $116 \mathrm{~mm}$ e temperatura média de $21,1^{\circ} \mathrm{C}$ (Sistema de monitoramento agrometeorológico, 2012). Farias Neto et al. (2006), ao avaliar o efeito da umidade na ocorrência e no desenvolvimento da PVR, com parcelas irrigadas em diferentes fases fenológicas e lâminas d'água, concluíram que o desenvolvimento dos sintomas da PVR é altamente favorecido pela elevada umidade no solo, especialmente nas fases reprodutivas $\mathrm{R} 4$ e $\mathrm{R} 5$.

Para a massa de mil grãos em ambas as safras e a produtividade da soja na safra de $2006 / 2007$, não foram observadas diferenças significativas entre os sistemas de preparo do solo (Tabela 1). Esses dados corroboram os de Silveira et al. (2003), que verificaram que o sistema de preparo do solo não afeta a produtividade da soja.

Contudo, para a produtividade de soja na safra de 2007/2008, observou-se aumento significativo no tratamento com solo revolvido, com incremento de $125 \mathrm{~kg} \mathrm{ha}^{-1}$ (Tabela 1). A menor produtividade no tratamento com plantio direto pode ser atribuída à compactação do solo na camada superficial ou subsuperficial (Kluthcouski et al., 2000). Já Santos et al. (2006b) verificaram que, independentemente de rotação, a soja cultivada sob plantio direto e sob cultivo mínimo apresenta maior produtividade, maior massa de mil grãos e maior altura de plantas, em comparação à soja cultivada sob preparo convencional de solo.

Tabela 1. Número de propágulos de Fusarium spp. no solo, massa de mil grãos e produtividade da soja nos tratamentos preparo do solo e coberturas de inverno, nas safras de 2006/2007 e 2007/2008 ${ }^{(1)}$.

\begin{tabular}{|c|c|c|c|c|c|c|}
\hline \multirow[t]{2}{*}{ Tratamento } & \multicolumn{2}{|c|}{ Fusarium spp. (№ de propágulos por g de solo) } & \multicolumn{2}{|c|}{ Massa de mil grãos (g) } & \multicolumn{2}{|c|}{ Produtividade $\left(\mathrm{kg} \mathrm{ha}^{-1}\right)$} \\
\hline & $2006 / 2007$ & $2007 / 2008$ & $2006 / 2007$ & $2007 / 2008$ & $2006 / 2007$ & $2007 / 2008$ \\
\hline \multicolumn{7}{|l|}{ Preparo do solo } \\
\hline Solo revolvido ${ }^{(2)}$ & $43,2 b$ & $34,7 \mathrm{a}$ & $205,9 a$ & $198,5 \mathrm{a}$ & $4.702,5 \mathrm{a}$ & $3.350,9 \mathrm{a}$ \\
\hline Plantio direto & $34,0 \mathrm{a}$ & $25,8 \mathrm{a}$ & $204,0 \mathrm{a}$ & $200,3 a$ & $4.676,7 \mathrm{a}$ & $3.225,8 b$ \\
\hline$\overline{\mathrm{DMS}}$ & 4,7 & 19,0 & 8,7 & 19,4 & 1257 & 67,3 \\
\hline $\mathrm{CV}(\%)$ & 7,8 & 61,9 & 3,8 & 8,7 & 24,1 & 1,8 \\
\hline \multicolumn{7}{|l|}{ Cobertura de inverno ${ }^{(3)}$} \\
\hline Pousio & $47,4 b$ & $27,0 \mathrm{a}$ & $204,5 \mathrm{a}$ & $201,4 a$ & $4.715,7 \mathrm{ab}$ & $3.406,4 a$ \\
\hline Aveia-preta 40 & $38,0 \mathrm{c}$ & $25,6 \mathrm{a}$ & $207,9 a$ & $198,5 \mathrm{a}$ & $4.992,8 \mathrm{a}$ & $3.205,6 \mathrm{a}$ \\
\hline Aveia-preta 80 & $28,3 \mathrm{~d}$ & $42,1 \mathrm{a}$ & $203,7 \mathrm{a}$ & $195,7 \mathrm{a}$ & $4.642,7 \mathrm{ab}$ & $3.221,2 \mathrm{a}$ \\
\hline Aveia-preta + ervilhaca & $56,1 \mathrm{a}$ & $34,0 \mathrm{a}$ & $204,1 \mathrm{a}$ & $201,0 \mathrm{a}$ & $4.431,5 b$ & $3.236,7 \mathrm{a}$ \\
\hline Azevém & $23,1 \mathrm{~d}$ & $29,5 \mathrm{a}$ & $204,6 \mathrm{a}$ & $200,5 \mathrm{a}$ & $4.515,4 b$ & $3.372,0 \mathrm{a}$ \\
\hline$\overline{\mathrm{DMS}}$ & 7,7 & 18,5 & 13,1 & 7,2 & 401,4 & 304,8 \\
\hline CV $(\%)$ & 11,3 & 40,5 & 5,1 & 2,9 & 8,2 & 7,4 \\
\hline
\end{tabular}

Pesq. agropec. bras., Brasília, v.47, n.4, p.528-533, abr. 2012 
Os tratamentos com as diferentes coberturas de inverno na safra de 2006/2007 (Tabela 1) apresentaram diferenças significativas quanto ao número de propágulos de Fusarium spp. no solo e quanto à produtividade de soja. A cobertura com aveia-preta + ervilhaca apresentou maior número de propágulos de Fusarium spp. no solo. Neste mesmo tratamento, observou-se menor produtividade de soja do que a observada no tratamento aveia-preta cultivada com $40 \mathrm{~kg} \mathrm{ha}^{-1}$ de sementes, na safra de 2006/2007. A cobertura com aveia-preta cultivada com $40 \mathrm{~kg}$ de sementes e a cobertura com azevém proporcionaram as menores quantidades de propágulos do fungo no solo. Na safra de 2007/2008, após a influência do segundo ano dos tratamentos com diferentes coberturas de inverno, não foi observada diferença significativa para o número de propágulos de Fusarium spp. por grama de solo seco, a massa de mil sementes e a produtividade de soja entre os tratamentos. Assim, as plantas de cobertura, após dois anos de cultivo, influenciaram a estabilidade do número de propágulos de Fusarium spp. no solo entre os tratamentos avaliados.

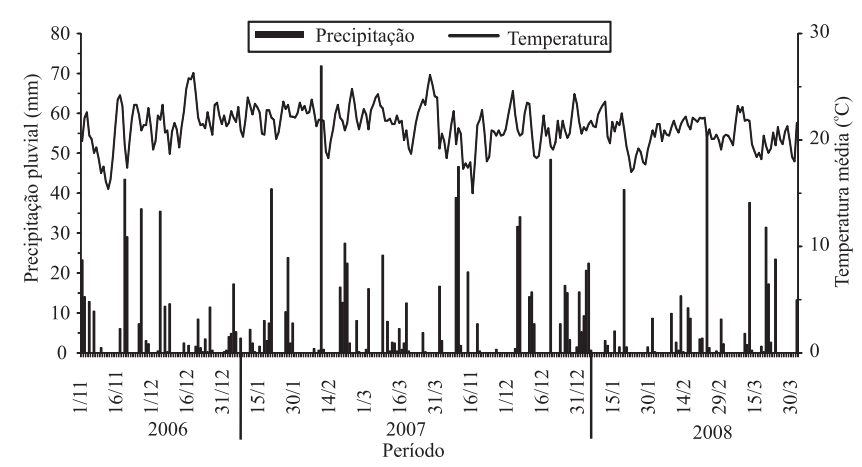

Figura 1. Precipitação pluvial e temperatura média do ar entre 1/11/2006 a 31/3/2007 e 1/11/2007 a 30/3/2008 em Ponta Grossa, PR (Sistema de monitoramento agrometeorológico, 2012).
Esses resultados confirmam os de Toledo-Souza et al. (2008), que relataram que plantios prévios de gramíneas, em geral, são supressores da população de Fusarium spp. em áreas infestadas, enquanto plantios prévios de leguminosas tendem a favorecer o aumento da população desse patógeno.

As cultivares CD 206 e FT Fênix apresentaram sintomas de PVR, avaliados no estádio fenológico R6 da soja. Na safra de 2006/2007, a incidência da PVR no sistema radicular da cultivar FT Fênix foi significativamente menor, em comparação à cultivar CD 206 (Tabela 2). No entanto, não foi observada diferença na safra de 2007/2008. A incidência de PVR nas folhas da cultivar FT Fênix foi superior à da cultivar CD 206, em ambos os anos. A massa de mil grãos da cultivar FT Fênix foi significativamente maior que a da CD 206, mas não houve diferença significativa entre as cultivares quanto à produtividade. Farias Neto et al. (2006), ao trabalhar com parcelas submetidas à inoculação e não inoculadas com Fusarium spp., observaram reduções em produtividade de grãos de até $27 \%$, em cultivares suscetíveis, que apresentaram severos sintomas foliares. Contudo, os sintomas iniciais, nessas cultivares, foram observados nos estádios R4 e R5, anteriores aos verificados no presente trabalho. Apesar da divergência de resultados, sabe-se que a resistência das plantas a essa doença é descrita como parcial, uma vez que, sob alta pressão de inóculo, mesmo os genótipos resistentes podem apresentar sintoma típico da PVR (Mueller et al., 2002; Silva et al., 2002), sem terem sua produtividade afetada.

A cultivar CD 206 apresentou maior número de vagens e grãos, quando comparada à cultivar FT Fênix, em plantas sem ou com a incidência de PVR (Tabela 3). O preparo do solo e as coberturas de inverno não afetaram o número de vagens e grãos, nas plantas sem ou com a incidência de PVR.

Tabela 2. Incidência de podridão-vermelha-da-raiz da soja (IPVRS) na raiz e na folha de plantas de soja, massa de mil grãos e produtividade das cultivares de soja CD 206 e FT Fênix, nas safras de 2006/2007 e 2007/2008 ${ }^{(1)}$.

\begin{tabular}{|c|c|c|c|c|c|c|c|c|}
\hline \multirow[t]{2}{*}{ Cultivar } & \multicolumn{2}{|c|}{ IPVRS na raiz $(\%)$} & \multicolumn{2}{|c|}{ IPVRS na folha (\%) } & \multicolumn{2}{|c|}{ Massa de mil grãos (g) } & \multicolumn{2}{|c|}{ Produtividade $\left(\mathrm{kg} \mathrm{ha}^{-1}\right)$} \\
\hline & $2006 / 2007$ & $2007 / 2008$ & $2006 / 2007$ & $2007 / 2008$ & $2006 / 2007$ & $2007 / 2008$ & $2006 / 2007$ & $2007 / 2008$ \\
\hline CD 206 & $51,7 \mathrm{~b}$ & $82,6 a$ & $1,2 \mathrm{a}$ & $1,4 \mathrm{a}$ & $166,9 \mathrm{a}$ & $155,0 \mathrm{a}$ & $4.706,2 \mathrm{a}$ & $3.249,2 \mathrm{a}$ \\
\hline FT Fênix & $39,9 a$ & $77,6 \mathrm{a}$ & $1,7 \mathrm{~b}$ & $2,4 \mathrm{~b}$ & $243,0 \mathrm{~b}$ & $243,8 b$ & $4.673,0 \mathrm{a}$ & $3.327,6 \mathrm{a}$ \\
\hline DMS & 7,0 & 6,4 & 0,4 & 0,8 & 4,7 & 2,9 & 230,2 & 113,0 \\
\hline $\mathrm{CV}(\%)$ & 28,7 & 14,9 & 57,8 & 83,8 & 4,3 & 2,7 & 9,1 & 6,3 \\
\hline
\end{tabular}

${ }^{(1)}$ Médias seguidas de letras iguais, nas colunas, não diferem pelo teste de Tukey, a 5\% de probabilidade. 
Tabela 3. Número médio de vagens e grãos das plantas com e sem sintomas de podridão-vermelha-da-raiz (PVR), das cultivares de soja CD 206 e FT Fênix, nos tratamentos preparo do solo e cobertura de inverno na safra de 2007/2008 ${ }^{(1)}$.

\begin{tabular}{lccccc}
\hline Tratamento & \multicolumn{2}{c}{ Sem sintoma de PVR } & & Com sintoma de PVR \\
\cline { 2 - 3 } & Vagem & Semente & & Vagem & Semente \\
\hline Preparo do solo & & & & \\
Solo revolvido ${ }^{(2)}$ & $36,2 \mathrm{a}$ & $71,2 \mathrm{a}$ & & $36,8 \mathrm{a}$ & $74,0 \mathrm{a}$ \\
Plantio direto & $35,7 \mathrm{a}$ & $72,3 \mathrm{a}$ & & $37,1 \mathrm{a}$ & $75,3 \mathrm{a}$ \\
\hline DMS & 5,5 & 8,52 & 6,9 & 14,3 \\
CV (\%) & 13,8 & 10,6 & 16,9 & 17,3 \\
\hline Cobertura de inverno ${ }^{(3)}$ & & & & \\
Pousio & $34,8 \mathrm{a}$ & $72,9 \mathrm{a}$ & $34,3 \mathrm{a}$ & $71,9 \mathrm{a}$ \\
Aveia-preta 40 & $37,6 \mathrm{a}$ & $75,2 \mathrm{a}$ & $35,2 \mathrm{a}$ & $69,4 \mathrm{a}$ \\
Aveia-preta 80 & $35,6 \mathrm{a}$ & $70,9 \mathrm{a}$ & $38,5 \mathrm{a}$ & $77,4 \mathrm{a}$ \\
Aveia-preta + ervilhaca & $36,5 \mathrm{a}$ & $69,1 \mathrm{a}$ & $37,2 \mathrm{a}$ & $74,4 \mathrm{a}$ \\
Azevém & $35,4 \mathrm{a}$ & $71,2 \mathrm{a}$ & $39,6 \mathrm{a}$ & $80,2 \mathrm{a}$ \\
\hline DMS & 5,0 & 11,8 & 6,1 & 10,9 \\
CV (\%) & 11,1 & 13,1 & 13,3 & 11,7 \\
\hline Cultivar & & & & \\
CD 206 & $41,1 \mathrm{a}$ & $87,6 \mathrm{a}$ & $42,1 \mathrm{a}$ & $90,5 \mathrm{a}$ \\
FT Fênix & $30,8 \mathrm{~b}$ & $56,2 \mathrm{~b}$ & $31,8 \mathrm{~b}$ & $58,8 \mathrm{~b}$ \\
\hline DMS & 1,5 & 5,0 & 2,3 & 4,2 \\
CV (\%) & 7,7 & 13,1 & 11,5 & 10,6 \\
\hline
\end{tabular}

${ }^{(1)}$ Médias seguidas de letras iguais, nas colunas, não diferem entre si pelo teste de Tukey, a $5 \%$ de probabilidade. ${ }^{(2)}$ Solo revolvido até a profundidade de $25 \mathrm{~cm}$. ${ }^{(3)}$ Aveia-preta 40, $40 \mathrm{~kg} \mathrm{ha}^{-1}$ de sementes; Aveia-preta 80, $80 \mathrm{~kg} \mathrm{ha}^{-1}$ de sementes e adição de $20 \mathrm{~kg} \mathrm{ha}^{-1}$ de N, na forma de ureia; Aveia-preta + ervilhaca, $50 \mathrm{~kg} \mathrm{ha}^{-1}$ de sementes para cada espécie; e Azevém, $60 \mathrm{~kg} \mathrm{ha}^{-1}$ de sementes.

\section{Conclusões}

1. Os sistemas de preparo de solo (solo revolvido ou plantio direto) e as coberturas de inverno não influenciam o número de propágulos de Fusarium spp. no solo, no segundo ano de manejo; entretanto, no primeiro ano, o plantio direto e o uso de aveia-preta e azevém reduzem o número de propágulos de Fusarium spp. no solo.

2. O plantio de aveia-preta e azevém aumenta a produtividade da soja apenas no primeiro ano de manejo, enquanto o revolvimento do solo proporciona aumento de produtividade da soja, no segundo ano de manejo.

3. A produtividade das cultivares de soja CD 206 e FT Fênix não foi afetada pela incidência de podridão-vermelha-da-raiz (PVR); no entanto, a cultivar FT Fênix foi mais susceptível à incidência de PVR na raiz e nas folhas.

\section{Referências}

ALMEIDA, A.M.R.; FERREIRA, L.P.; YORINORI, J.T.; SILVA, J.F.V.; HENNING, A.A.; GODOY, C.V.; COSTAMILAN, L.M.; MEYER, M.C. Doenças da soja (Gycine max). In: KIMATI, H.; AMORIM, L.; REZENDE, J.A.M.; BERGAMIN FILHO, A.; CAMARGO, L. E.A. (Ed.). Manual de fitopatologia: doenças das plantas cultivadas. 4.ed. São Paulo: Ceres, 2005. p.569-588.

ALMEIDA, A.M.R.; SARAIVA, O.F.; FARIAS, J.R.B.; GAUDENCIO, C.A.; TORRES, E. Survival of pathogens on soybean debris under no-tillage and conventional tillage systems. Pesquisa Agropecuária Brasileira, v.36, p.1231-1238, 2001.

AOKI, T.; O'DONNELL, K.; SCANDIANI, M.M. Sudden death syndrome of soybean in South America is caused by four species of Fusarium: Fusarium brasiliensis sp. nov., F. cuneirostrum sp. nov., $F$ tucumaniae, and F. virguliforme. Mycoscience, v.46, p.162-183, 2005.

ARRUDA, G.M.T.; MILLER, R.N.G.; FERREIRA, M.A.S.V.; CAFÉ-FILHO, A.C. Morphological and molecular characterization of the sudden death syndrome pathogen of soybean in Brazil. Plant Pathology, v.54, p.53-65, 2005.

BAPTISTA, M.J.; REIS JUNIOR, F.B. dos; XAVIER, G.R.; ALCÂNTARA, C. de; OLIVEIRA, A.R. de; SOUZA, R.B.; LOPES, C.A. Eficiência da solarização e biofumigação do solo no controle da murcha-bacteriana do tomateiro no campo. Pesquisa Agropecuária Brasileira, v.42, p.933-938, 2007.

CAVIGLIONE, J.H.; KIIHL, L.R.B.; CARAMORI, P.H.; OLIVEIRA, D. de. Cartas climáticas do Paraná. Londrina: IAPAR, 2000.

FARIAS NETO, A.L. de; HARTMAN, G.L.; PEDERSEN, W.L.; LI, S.; BOLLERO, G.A.; DIERS, B.W. Irrigation and inoculation treatments that increase the severity of soybean sudden death syndrome in the field. Crop Science, v.46, p.2547-2554, 2006.

FENILE, R.C.; SOUSA, N.L. de. Efeitos de materiais orgânicos e da umidade do solo na patogenicidade de Rhizoctonia solani Kuhn GA-4 HGI ao feijoeiro. Pesquisa Agropecuária Brasileira, v.34, p.1959-1967, 1999.

GABRIEL FILHO, A.; STROHHAECKER, L.; FEY, E. Profundidade e espaçamento da mandioca no plantio direto na palha. Ciência Rural, v.33, p.461-467, 2003.

GÁSPERI, A.C.; PRESTES, A.M.; COSTAMILAN, L.M. Reação de cultivares de soja à podridão vermelha da raiz causada por Fusarium solani f. sp. glicynes. Fitopatologia Brasileira, v.28, p.544-547, 2003.

KLUTHCOUSKI, J.; FANCELLI, A.L.; DOURADO NETO, D.; RIBEIRO, C.M.; FERRANO, L.A. Manejo do solo e o rendimento da soja, milho, feijão e arroz em plantio direto. Scientia Agricola, v.57, p.97-104, 2000.

MUELLER, D.S.; HARTMAN, G.L.; NELSON, R.L.; PEDERSEN, W.L. Evaluation of Glycine max germplasm for resistance to Fusarium solani f. sp. glycines. Plant Disease, v.86, p.741-746, 2002. 
NASH, S.M.; SNYDER, W.C. Quantitative estimations by plate counts of propagules of the bean root rot Fusarium in field soils. Phytopathology, v.52, p.567-572, 1962.

SANTOS, H.G. dos; JACOMINE, P.K.T.; ANJOS, L.H.C. dos; OLIVEIRA, V.A. de; OLIVEIRA, J.B. de; COELHO, M.R.; LUMBRERAS, J.F.; CUNHA, T.J.F. (Ed.). Sistema brasileiro de classificação de solos. 2.ed. Rio de Janeiro: Embrapa Solos, 2006a. $306 \mathrm{p}$.

SANTOS, H.P. dos; LHAMBY, J.C.B.; SPERA, S.T. Rendimento de grãos de soja em função de diferentes sistemas de manejo de solo e de rotação de culturas. Ciência Rural, v.36, p.21-29, 2006 b.

SILVA, J.F.V.; CARNEIRO, G.E.S.; YORINORI, J.T.; ALMEIDA, A.M.R.; ARIAS, C.A.A.; KIIHL, R.A.S.; ALMEIDA, L.A.; OLIVEIRA, E.; LIMA, C.G.; SCHOBER, I.C.; GOULART FILHO, G.; ALIGLIERI, G.M.G.; GOMES, J.I.; SOUZA, N.V.; BENATO, L.C. Contribuição ao desenvolvimento de linhagens de soja com resistência a patógenos. Londrina: Embrapa Soja, 2002. 43p. (Embrapa Soja. Boletim de pesquisa e desenvolvimento, 1).

SILVEIRA, P.M. da; STONE, L.F. Sistemas de preparo do solo e rotação de culturas na produtividade de milho, soja e trigo. Revista Brasileira de Engenharia Agrícola e Ambiental, v.7, p.240-244, 2003.

SISTEMA de monitoramento agrometeorológico. Disponível em: $<$ http://sma2.fundacaoabc.org.br/servicos/solicitacao_dados $>$. Acesso em: 2 abr. 2012.

TECNOLOGIAS de produção de soja - região central do Brasil 2007. Londrina: Embrapa Soja, 2006. 199p. (Embrapa Soja. Sistemas de produção, 11).

TOLEDO-SOUZA, E.D. de; SILVEIRA, P.M. da; LOBO JUNIOR, M.; CAFÉ FILHO, A.C. Sistemas de cultivo, sucessões de culturas, densidade do solo e sobrevivência de patógenos de solo. Pesquisa Agropecuária Brasileira, v.43, p.971-978, 2008.

Recebido em 24 de setembro de 2011 e aprovado em 14 de março de 2012 